\title{
What is the evidence for transmission of COVID-19 by children in schools? A living systematic review
}

Wei Xu${ }^{1 *}$, Xue $\mathrm{Li}^{1,2 *}$, Marshall Dozier ${ }^{3}$, Yazhou $\mathrm{He}^{1}$, Amir Kirolos ${ }^{1,4}$, Zhongyu Lang $^{1}$, Catherine Mathews ${ }^{5}$, Nandi Siegfried $^{5}$, Evropi Theodoratou ${ }^{1,6}$; on behalf of UNCOVER

\footnotetext{
${ }^{1}$ Centre for Global Health Research, Usher Institute, University of Edinburgh, Edinburgh, UK ${ }^{2}$ School of Public Health and the Second Affiliated Hospital, Zhejiang University, Hangzhou, China

${ }^{3}$ Information Services, University of Edinburgh, Edinburgh, UK

${ }^{4}$ Department of Clinical Infection, Microbiology \& Immunology, Institute of Infection, Veterinary \& Ecological Sciences, University of Liverpool, Liverpool, UK

${ }^{5}$ Health Systems Research Unit, South African Medical Research Council, Parow, South Africa

${ }^{6}$ Cancer Research UK Edinburgh Centre, Medical Research Council Institute of Genetics and Molecular Medicine, University of Edinburgh, Edinburgh, UK

*Joint first authorship.
}

\section{Correspondence to:}

Prof Evropi Theodoratou

Centre for Global Health

Usher Institute

Teviot Place

University of Edinburgh

Edinburgh EH8 9AG

UK

e.theodoratou@ed.ac.uk

Dr Nandi Siegfried

Health Systems Research Unit

South African Medical Research Council

Parow

South Africa

nandi.siegfried@gmail.com
Background It is of paramount importance to understand the transmission of SARS-CoV-2 in schools, which could support the decision-making about educational facilities closure or re-opening with effective prevention and control measures in place.

Methods We conducted a systematic review and meta-analysis to investigate the extent of SARS-CoV-2 transmission in schools. We performed risk of bias evaluation of all included studies using the Newcastle-Ottawa Scale (NOS).

Results 2178 articles were retrieved and 11 studies were included. Five cohort studies reported a combined 22 student and 21 staff index cases that exposed 3345 contacts with 18 transmissions (overall infection attack rate (IAR): 0.08\%, 95\% confidence interval $(\mathrm{CI})=0.00 \%-0.86 \%)$. IARs for students and school staff were $0.15 \%$ (95\% CI $=0.00 \%-0.93 \%)$ and $0.70 \%(95 \% \mathrm{CI}=0.00 \%-$ $3.56 \%)$ respectively. Six cross-sectional studies reported 639 SARS-CoV-2 positive cases in 6682 study participants tested [overall SARS-CoV-2 positivity rate: $8.00 \%$ (95\% CI $=2.17 \%$ $16.95 \%)$. SARS-CoV-2 positivity rate was estimated to be $8.74 \%$ (95\% CI $=2.34 \%-18.53 \%$ ) among students, compared to $13.68 \%$ (95\% CI $=1.68 \%-33.89 \%)$ among school staff. Gender differences were not found for secondary infection $(\mathrm{OR}=1.44,95 \%$ $\mathrm{CI}=0.50-4.14, \mathrm{P}=0.49)$ and SARS-CoV-2 positivity $(\mathrm{OR}=0.90$, $95 \% \mathrm{CI}=0.72-1.13, \mathrm{P}=0.36)$ in schools. Fever, cough, dyspnea, ageusia, anosmia, rhinitis, sore throat, headache, myalgia, asthenia, and diarrhoea were all associated with the detection of SARSCoV-2 antibodies (based on two studies). Overall, study quality was judged to be poor with risk of performance and attrition bias, limiting the confidence in the results.

Conclusions There is limited high-quality evidence available to quantify the extent of SARS-CoV-2 transmission in schools or to compare it to community transmission. Emerging evidence suggests lower IAR and SARS-CoV-2 positivity rate in students compared to school staff. Future prospective and adequately controlled cohort studies are necessary to confirm this finding.

Globally, there have been at least 29737453 confirmed Coronavirus Disease 2019 (COVID-19) cases and 937391 deaths have occurred in 216 countries/territories according to the report of WHO from 17 
September 2020 [1]. In response to the pandemic of novel COVID-19 caused by a severe acute respiratory syndrome coronavirus 2 (SARS-CoV-2), 107 countries had implemented national school closures by March 182020 to reduce transmission [2].

Initial evidence suggests children have lower susceptibility and relatively small proportion of infections, compared to adults [3]. Children also have milder cases and better prognosis than adults [4]. According to data from 29 countries, the proportion of children among COVID-19 cases varies from 0.3\% (lowest in Spain) up to 13.8\% (highest in Argentina) [5].

Many schools closed at the beginning of the COVID-19 pandemic and therefore it is not known whether children are at risk of higher transmission in school settings compared to community settings. Multiple countries around the world have now re-opened schools for face-to-face teaching with varying non-pharmaceutical interventions (NPIs) in place including physical distancing measures, wearing of face masks, enhanced hand hygiene, reduced class sizes, and staggered class start and end times [6]. Evidence on SARS-CoV-2 transmission in schools could support decision-making about schools/childcare facilities closure or re-opening with effective COVID-19 prevention and control measures in place.

A living systematic review to investigate the evidence of SARS-CoV-2 transmission in the school environment is presented. We aim to keep updating this systematic review to include new studies as they become available and to re-evaluate the conclusions given the rapid pace of ongoing research.

\section{METHODS}

\section{Protocol}

The protocol of this living systematic review was developed in accordance with the reporting guidance in the Preferred Reporting Items for Systematic Reviews and Meta-Analyses Protocols (PRISMA-P) statement [7] and was registered on PROSPERO (register number: CRD42020192839) [8].

\section{Literature search and eligibility criteria}

We ran a systematic search in MEDLINE, CINAHL, ERIC, Embase, WHO COVID-19 database, medRxiv, The American Academy of Pediatrics (AAP), The Royal College of Paediatrics and Child Health (RCPCH), and Do not forget the bubbles websites with entry date limits from December 2019 to 14 July 2020 (please see search strategies in Appendix S1 of the Online Supplementary Document), to identify studies that investigated SARS-CoV-2 transmission in schools. We ran an updated search in MEDLINE up to 14 September 2020. We further hand-searched reference lists of the retrieved eligible publications to identify additional relevant studies. We reviewed titles, abstracts, and subsequently full texts based on pre-defined inclusion and exclusion criteria following the population, exposure, comparison, outcome (PECO) approach. We included children (defined as $\leq 18$ years old) who were attending school, and their close contacts (family and household members, teachers, school support staff) during the COVID-19 pandemic. We excluded home-schooled children and their close contacts and schools with student numbers below 20. For study outcomes, we included infections traced to a school index case with a COVID-19 positive test. For study types, inclusion criteria spanned cohort studies regardless of active or passive follow-up in the exposed and non-exposed groups (eg, contact-tracing studies), viral genotyping studies, cross-sectional studies (eg, sero-surveillance studies, community prevalence studies before and after school opening). We included articles in peer-reviewed journals and pre-prints, and excluded comments, conference abstracts and interviews.

\section{Data extraction}

Data relevant to the evidence for SARS-CoV-2 transmission in schools were extracted including: citation details, publication type, study design, country, region, city, investigation period, background population setting (country/regional COVID-19 prevalence rates where reported), types of non-pharmaceutical intervention in the background population setting, school closures at the time of the study, number of schools included, type of schools, size of schools, types of non-pharmaceutical interventions in place in schools, sampling method (nasopharyngeal or oropharyngeal swabs/ serum samples), provider testing vs self-testing, testing method (PCR/ SARS-CoV-2 antibody testing), modality of follow-up, frequency of follow-up, case and contact demographics (age and gender), clinical characteristics, number of index cases, number of contacts, number of secondary infected cases, infection attack rates (IAR): No. of sec- 
ondary infected cases/ No. of contacts, number of participants tested for SARS-CoV-2, number of SARSCoV-2 positive cases, and SARS-CoV-2 positivity rates: No. of positive cases/ No. of participants tested. Data were extracted by one reviewer (WX) and checked by a second reviewer (YH).

\section{Meta-analysis}

We pooled together SARS-CoV-2 infection attack rates (IAR) and positivity rates using a random-effects model (DerSimonian-Laird) [9]. To account for zero cell counts, we transformed raw numbers/proportions with the Freeman-Tukey double arcine method to stabilize the variance [10].

We performed further random-effects meta-analyses (DerSimonian-Laird) of the association of SARSCoV-2 positivity with gender and clinical symptoms. Symptoms were further categorized as major (fever, cough, dyspnoea, anosmia and ageusia) or minor (sore throat, rhinitis, myalgia, diarrhoea, headache, asthenia) $[11,12]$.

Heterogeneity among studies was tested using Cochran's Q statistic, the $\mathrm{I}^{2}$ index, and the tau-squared test [13]. Funnel plots and the Egger test were used to detect evidence of publication bias [14]. $P<0.05$ was considered as statistically significant (two-sided).

\section{Assessment of methodological quality and risk of bias}

We applied the Newcastle Ottawa Scale (NOS) for controlled cohort studies to reflect the school setting [15] and used the NOS as a foundation to evaluate the quality of cross-sectional studies informed by earlier work [16]. The tools included an assessment of selection, measurement and attrition bias, and comparability. The tool is available in the supplementary materials (Appendix S2 of the Online Supplementary Document).

All statistical analyses were conducted using R, version 3.3.0 (R Foundation for Statistical Computing, Vienna, Austria).

\section{RESULTS}

The initial search retrieved 2178 articles. After screening, 11 studies were eligible for inclusion (Figure 1), including five cohort studies [17-21] and six cross-sectional studies [11,12,22-25]. We did not identify viral genotyping studies.

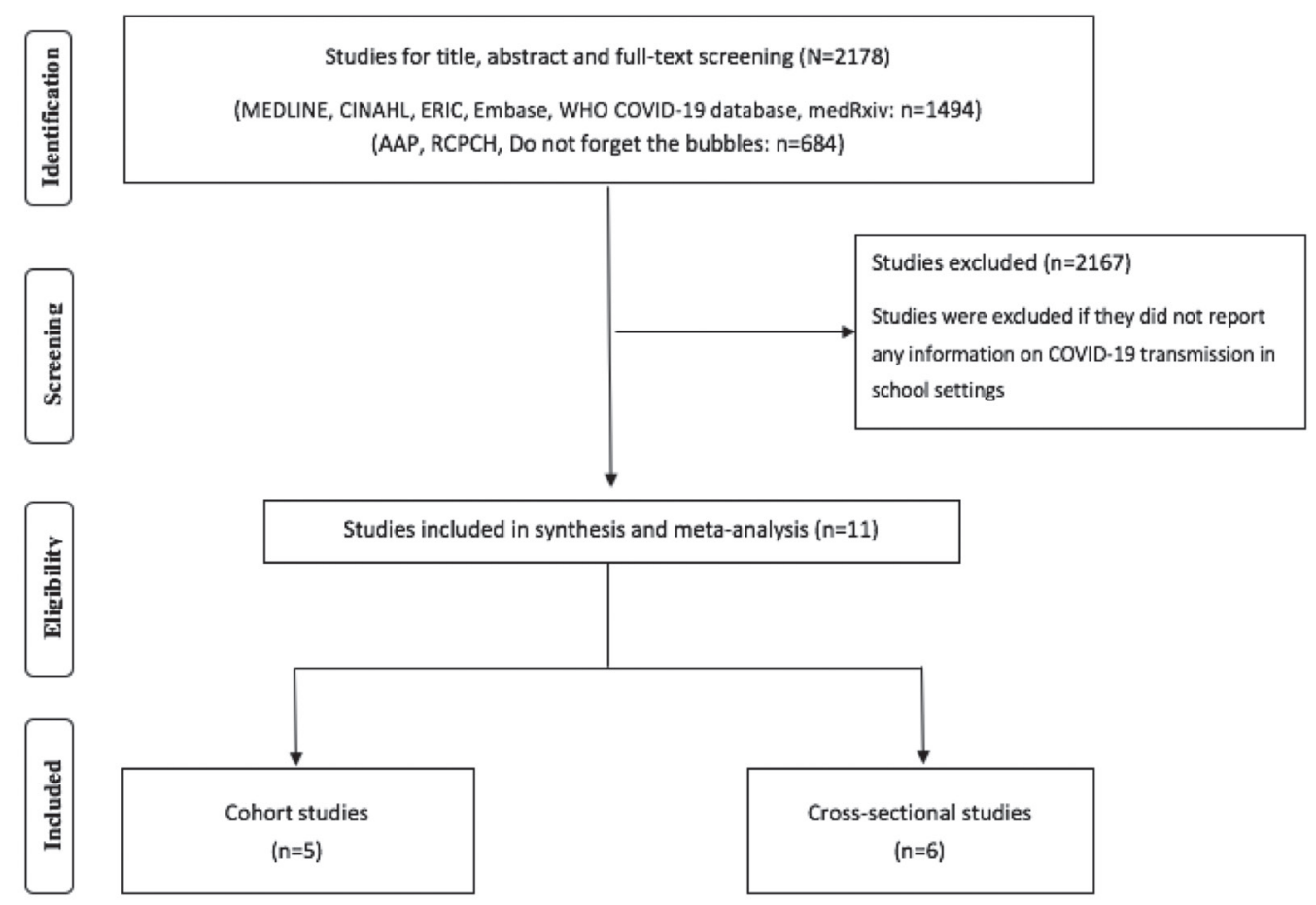

Figure 1. Flowchart summarizing study identification and selection. 


\section{Characteristics and quality of the included studies}

The study characteristics of the 11 included studies are presented in Table 1, Table 2, Table 3, and Table 4 .

Table 1. Characteristics of cohort studies $(\mathrm{N}=5)$

\begin{tabular}{|c|c|c|c|c|c|c|c|c|c|c|}
\hline Study & $\begin{array}{c}\text { Publication } \\
\text { type }\end{array}$ & $\begin{array}{l}\text { StUDY } \\
\text { DESIGN }\end{array}$ & Country & Region & City & $\begin{array}{l}\text { INVESTIGATION } \\
\text { PERIOD }\end{array}$ & $\begin{array}{l}\text { No. COVID-19 } \\
\text { CASES (BACKGROUND } \\
\text { POPULATION)* }\end{array}$ & $\begin{array}{l}\text { NON-PHARMACEUTI- } \\
\text { CAL INTERVENTIONS } \\
\text { (COUNTRV/RECION) }\end{array}$ & $\begin{array}{l}\text { SCHOOL } \\
\text { CLOSURES } \\
\text { (YES/ Nlo) }\end{array}$ & $\begin{array}{l}\text { SchoOL } \\
\text { CLOSURES } \\
\text { (DATE) }\end{array}$ \\
\hline Danis 2020 [17] & peer-review & cohort & France & Rhne-Alpes & $\begin{array}{l}\text { Les Contam- } \\
\text { ines-Montjoie }\end{array}$ & 24 Jan-16 Feb & $9[26]$ & NA & Yes & $8 \mathrm{Feb}$ \\
\hline Heavey 2020 [18] & peer-review & cohort & Ireland & NA & NA & 1-13 Mar & $90[27]$ & NA & No & $12 \mathrm{Mar}$ \\
\hline Yung 2020 [19] & peer-review & cohort & Singapore & NA & NA & Feb-Mar & $1189[28]$ & NA & No & NA \\
\hline NCIRS 2020 [20] & pre-print & cohort & Australia & $\begin{array}{c}\text { New South } \\
\text { Wales }\end{array}$ & NA & 10 Apr-3 Jul & 437 [29] & NA & $\begin{array}{l}\text { 10-28 } \\
\text { Apr: Yes; } \\
29 \text { Apr-3 } \\
\text { Jul: No }\end{array}$ & $\begin{array}{c}\text { 10-28 } \\
\text { Apr }\end{array}$ \\
\hline Macartney 2020 [21] & peer-review & cohort & Australia & $\begin{array}{c}\text { New South } \\
\text { Wales }\end{array}$ & NA & 25 Jan-9 Apr & 2779 [29] & NA & No & NA \\
\hline
\end{tabular}

*No. of COVID-19 cases for background population was not reported in original studies and was obtained from country's official website.

\section{Cohort studies}

A cluster outbreak in schools was reported in Australia New South Wales (NSW) during 25 January-9 April [21]. In NSW, 15 primary and secondary schools, and ten early childhood education and care (ECEC) settings had 27 primary SARS-CoV-2 positive cases including 12 children and 15 school staff attending while infectious, with 1448 contacts traced. Secondary transmission was reported in three schools and one ECEC. Eighteen secondary infected cases were found among a total of 1448 close contacts. IARs for primary school, secondary school, ECDC and overall were $0.92 \%, 0.00 \%, 2.25 \%$ and $1.24 \%$ respectively. Transmission rate of student-to-student was $0.31 \%$, and student-to-school staff was $0.97 \%$. By comparison, transmission rate of school staff-to-student was $1.49 \%$ and school staff-to-school staff was $4.38 \%$.

The remaining three studies in France (Les Contamines-Montjoie), Ireland, and Singapore and a follow-up of the NSW Australian study indicated that the extent of any student-to-student and/or student-to-school staff transmission is limited [17-20].

In France (Les Contamines-Montjoie), a 9-year-old child attended three different schools while symptomatic, and of the 102 contacts identified, no secondary infections occurred [17].

A study in Ireland investigated SARS-CoV-2 transmission in schools before school closures on 12 March and did not identify any cases of onward transmission to other students or school staff [18]. In this study, six primary COVID-19 cases including three students, one teacher and two adult visitors who attended educational sessions were identified and 1155 contacts (924 student contacts and 101 adult contacts) were identified.

During February and March, nationwide surveillance and contact-tracing in Singapore identified two SARSCoV-2 positive students (5-year-old and 12-year-old) who attended pre-school and secondary school on the first day of their symptoms before subsequently being diagnosed with COVID-19, and one school staff who worked in a pre-school [19]. Screening of 119 students and staff who were close contacts (secondary school: $\mathrm{n}=8$; pre-school 1: $\mathrm{n}=34$; pre-school 2: $\mathrm{n}=77$ ) did not detect any SARS-CoV-2 infection.

In the NSW follow-up study, (school term 2 of the academic year between 10 April and 3 July), six SARSCoV-2 positive cases including four students and two school staff attended three primary schools, two high schools and one ECEC while infectious, and 521 contacts (459 student contacts and 62 adult contacts) were identified [20]. No secondary infection was reported.

\section{Cross-sectional studies}

A study in Belgium measured the prevalence of SARS-CoV-2 in randomly sampled 84 children attending eight daycare centres during the period 2-12 March, and found all analyzed samples were negative for SARS-CoV-2 [25].

Four studies in Chile (Vitacura, Santiago), Germany (Saxony), and France (Crépy-en-Valois) identified antibody positive cases in schools, and overall seroprevalence varied from $0.01 \%$ to $25.87 \%[11,12,23,24]$. 


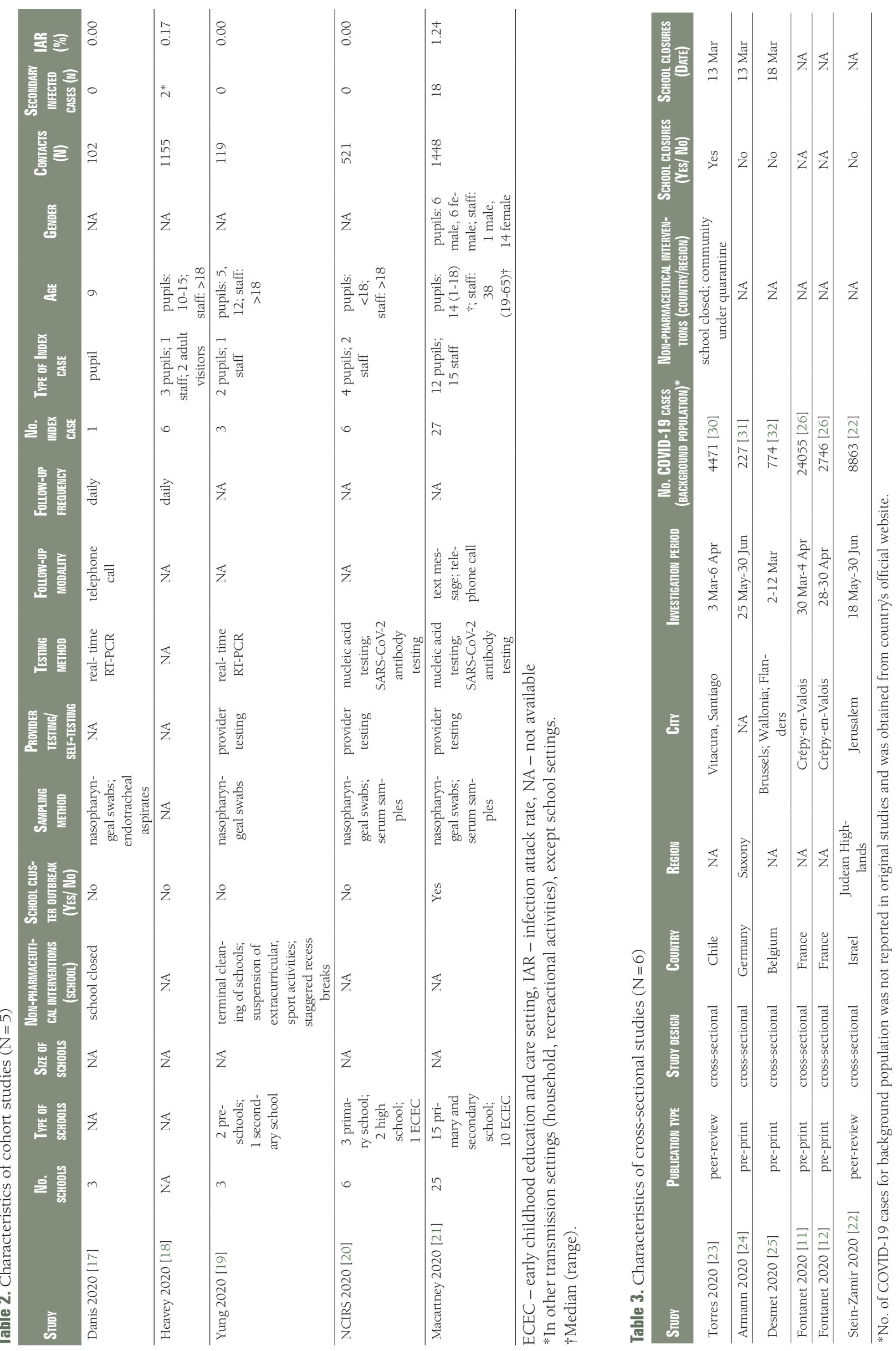



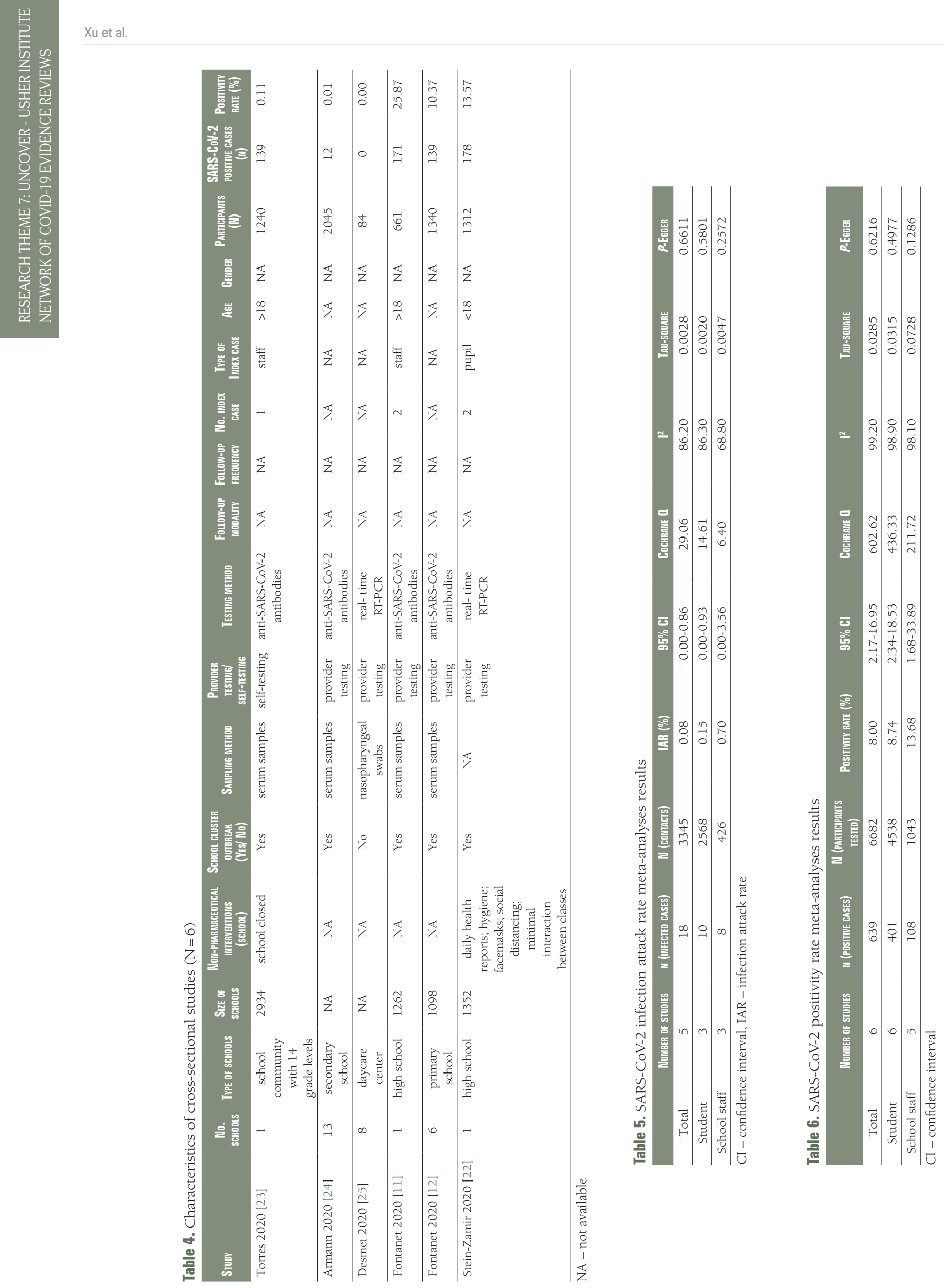
A large school community was closed on 13 March in Chile (Santiago) and during quarantine, a home-delivery and self-administered antibody test were conducted among 1009 students and 235 school staff [23]. Antibody positive rates were 9.91\% (100/1009) and 16.60\% (39/235) respectively. Antibody positive rates for pre-school, elementary school, middle school and high school were 12.24\%, 10.84\%, 11.80\% and $5.69 \%$. The peak rate was observed in pre-school.

After reopening of schools in Germany (Saxony) on 18 May, 1538 students from grade 8-11 and 507 teachers in 13 secondary schools were tested for SARS-CoV-2 antibody to investigate their role in SARSCoV-2 transmission in schools [24]. The overall antibody positive rate was $0.58 \%(12 / 2045)$, and $0.72 \%$ (11/1538) for student and 0.20\% (1/507) for school staff.

In France (Crépy-en-Valois), two sero-prevalence studies were conducted between 30 March-30 April in one high school $(n=661)$ and six primary schools $(n=1340)[11,12]$. Antibody positive rates were $25.87 \%$ (171/661) in the high school and 10.37\% (139/1340) in primary schools. Specifically, seropositivity prevalence was 38.33\% (92/240), 48.75\% (39/80) among students and staff in high school. By comparison, seropositivity prevalence was 8.82\% (45/510), 5.71\% (4/70) among students and staff in primary schools.

In Israel, ten days after schools reopened on 17 May, two index student cases were reported in a high school [22]. SARS-CoV-2 real-time PCR tests were provided to 1161 students and 151 school staff, a total of 178 positive cases (overall positivity: 13.57\%) including 153 students (student positivity: 13.18\%) and 25 school staff (staff positivity: 16.56\%) were identified. SARS-CoV-2 positive rates were higher in junior grades for students aged 12-14 years old than in high grades for students aged 15-18 years old. The peak rates were observed in the 9th grade (14 year-old, 32.62\%) and the 7th grade (12 year-old, 20.30\%).

\section{SARS-CoV-2 infection attack rate}

We combined SARS-CoV-2 IARs in schools in meta-analyses (Table 5). A total of five cohort studies early in pandemic before lockdown were included with 18 secondary infected cases in 3345 contacts [17-21]. The pooled IAR of total study participants was calculated to be $0.08 \%$ ( $95 \% \mathrm{CI}=0.00 \%-0.86 \%$ ) by using the Freeman-Tukey double arcine transformation and DerSimonian-Laird random-effects model (Figure 2, Panel A). The heterogeneity in this meta-analysis was substantial with an $\mathrm{I}^{2}$ value of $86.2 \%$. There was

A

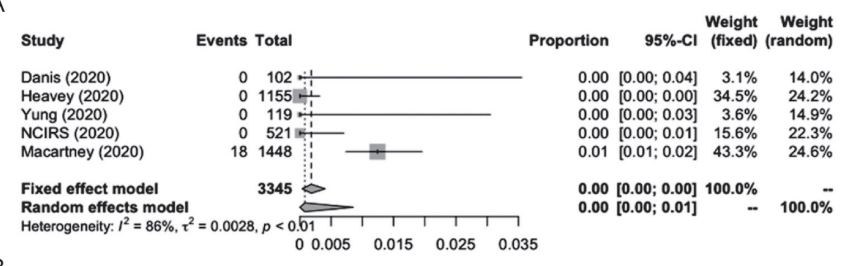

B

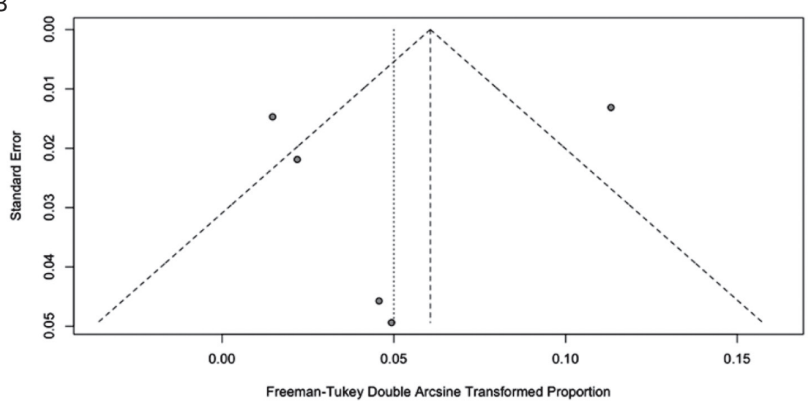

C

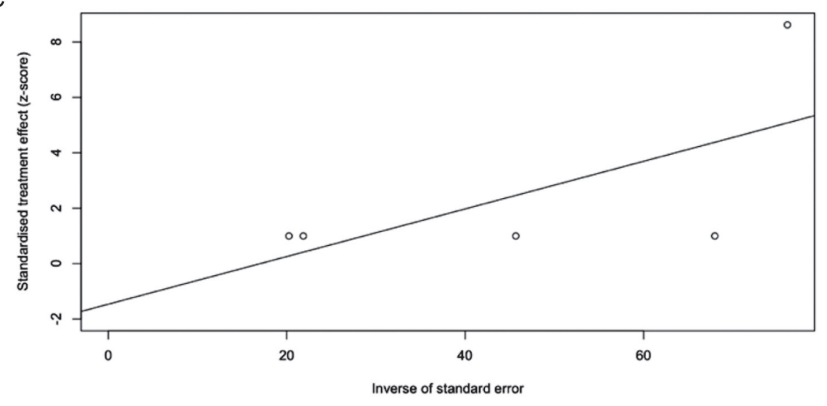

Figure 2. Overall infection attack rate. Panel A. Forest plot. Panel B. Funnel plot. Panel C. Egger's plot. no evidence of publication bias (Egger's test $P=0.661$;

Figure 2, Panel B and C).

We estimated the pooled IARs for students and school staff separately: $0.15 \%(95 \% \mathrm{CI}=0.00 \%-0.93 \%)$ and $0.70 \%$ (95\% CI =0.00\%-3.56\%), respectively (Figure 3, Panel A, and Figure 4, Panel A). Heterogeneity was high and there was no evidence of publication bias (Figure 3, Panel B and C; Figure 4, Panel B and C).

\section{SARS-CoV-2 positivity rate}

We also meta-analyzed SARS-CoV-2 positivity rates in schools (Table 6) from a total of six cross-sectional studies which included 639 SARS-CoV-2 positive cases in 6682 participants tested [11,12,22-25]. The result of the random effect meta-analysis showed that the pooled SARSCoV-2 positivity rate of total study participants was $8.00 \%$ (95\% CI =2.17\%-16.95\%) with substantial heterogeneity $\left(\mathrm{I}^{2}=99.2 \%\right)$ (Figure 5, Panel A), but no evidence of publication bias (Figure 5, Panel B and C).

Specifically, the positivity rates of SARS-CoV-2 was estimated to be $8.74 \%$ (95\% CI=2.34\%-18.53\%) among students (Figure 6, Panel A), compared to 13.68\% (95\% $\mathrm{CI}=1.68 \%-33.89 \%$ ) among school staff (Figure 7, Panel A). Heterogeneity was reported with $\mathrm{I}^{2}$ value of $98.9 \%$ and $98.1 \%$. Funnel plot with Egger's test $(P=0.498$ and 0.129 ) suggested that there was no notable evidence of publication bias (Figure 6, Panel B and C; Figure 7, Panel B and C). 
A
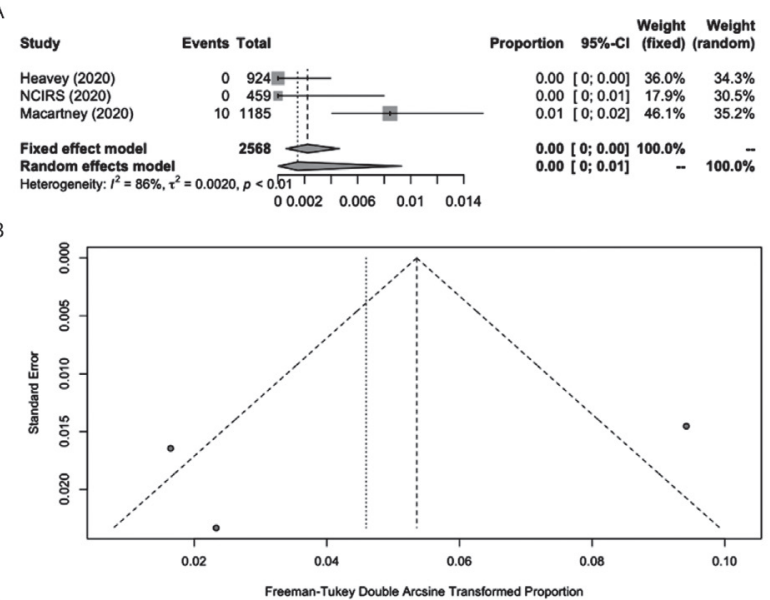

C

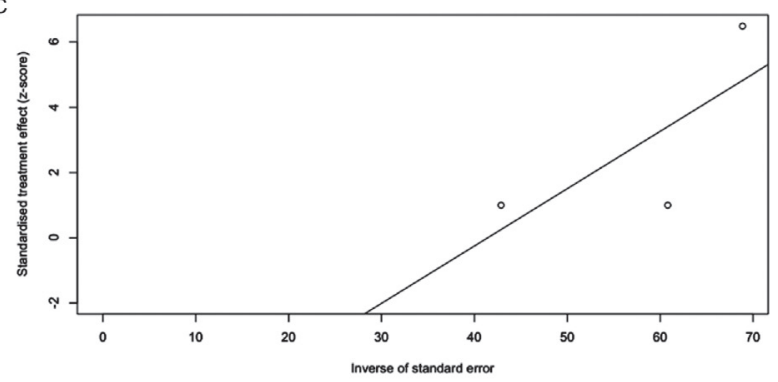

Figure 3. Student infection attack rate. Panel A. Forest plot. Panel B. Funnel plot. Panel C. Egger's plot.

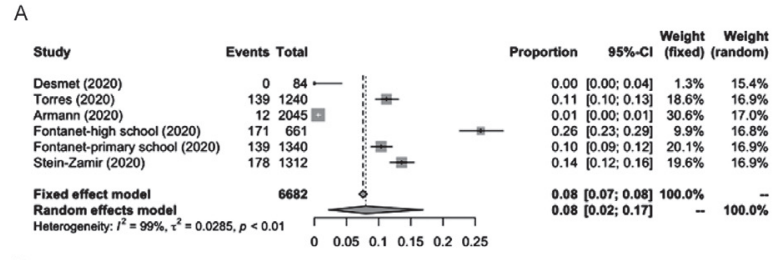

B

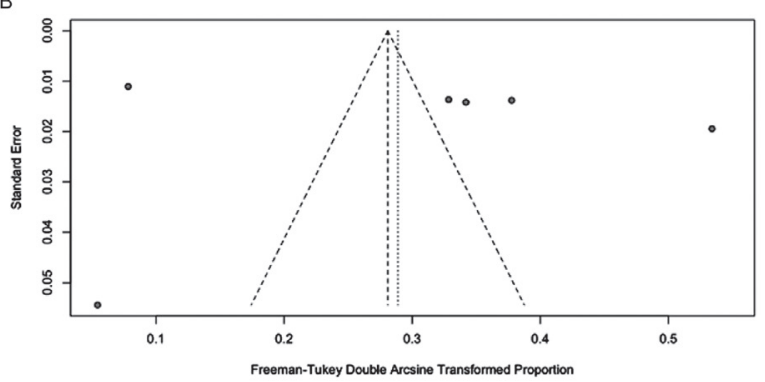

C

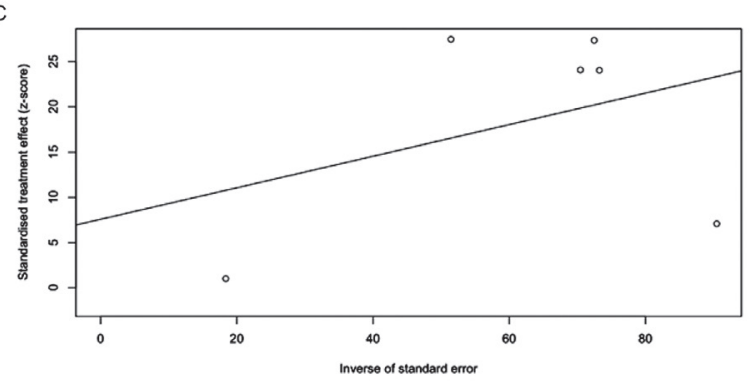

Figure 5. Overall SARS-CoV-2 positivity rate. Panel A. Forest plot. Panel B. Funnel plot. Panel C. Egger's plot.
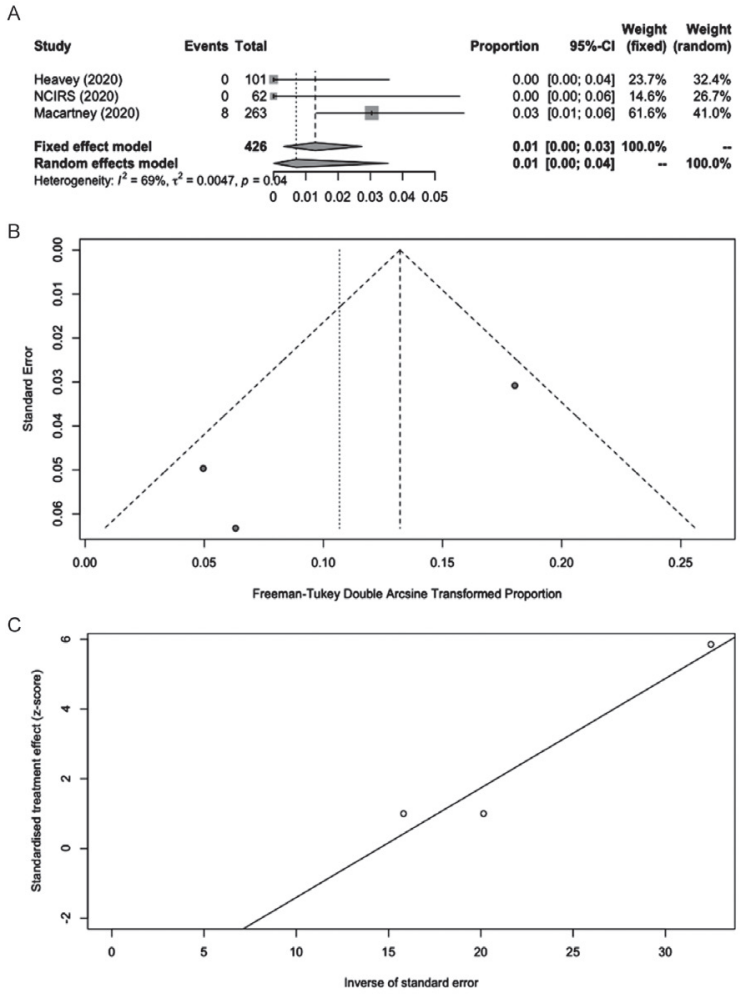

Figure 4. School staff infection attack rate. Panel A. Forest plot. Panel B. Funnel plot. Panel C. Egger's plot.
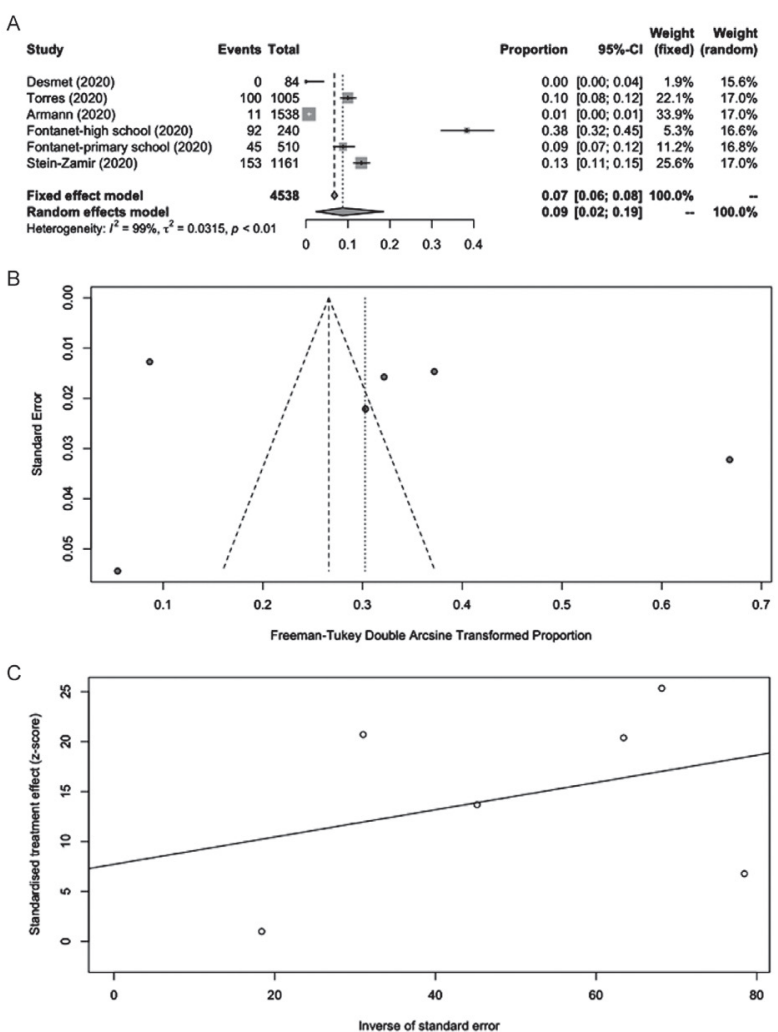

Figure 6. Student SARS-CoV-2 positivity rate. Panel A. Forest plot. Panel B. Funnel plot. Panel C. Egger's plot. 
A

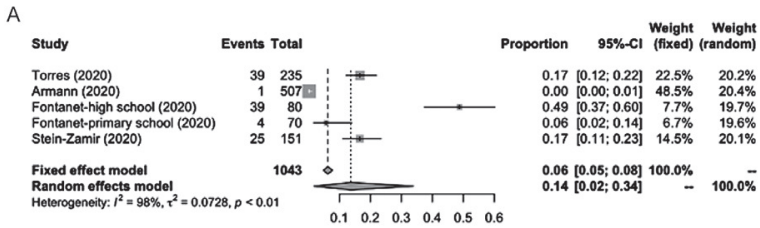

B

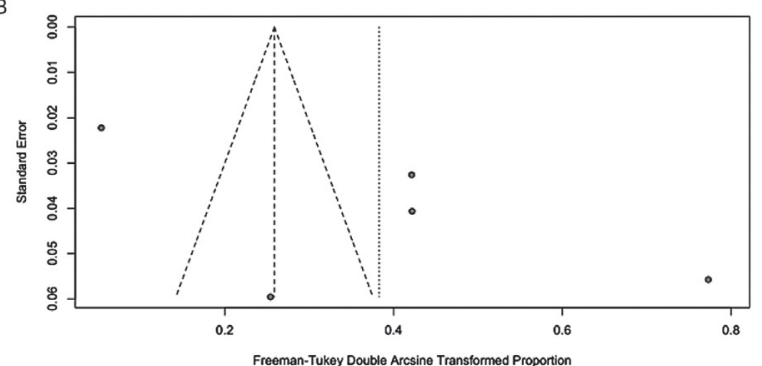

C

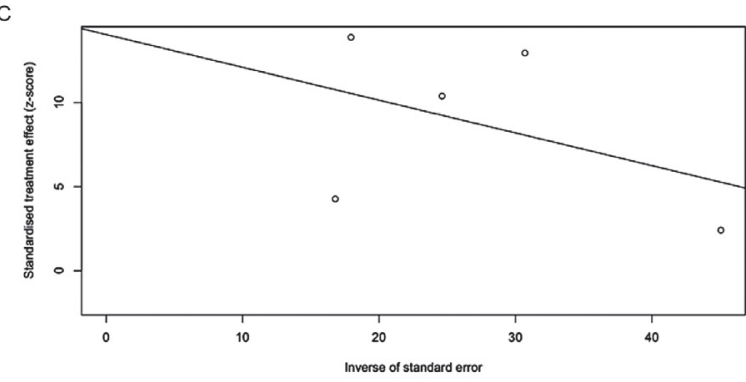

Figure 7. School staff SARS-CoV-2 positivity rate. Panel A. Forest plot. Panel B. Funnel plot. Panel C. Egger's plot.
Gender differences in SARS-CoV-2 infection attack rate and positivity rate

We did not find any gender differences for secondary infection $(\mathrm{OR}=1.44,95 \% \mathrm{CI}=0.50-4.14, P=0.49$, No. of cases in male/female group: 7/7) [21], and for SARS-CoV-2 positivity $(\mathrm{OR}=0.90,95 \% \mathrm{CI}=0.72-1.13, \mathrm{P}=0.36$, No. of cases in male/female group: 268/359) in schools (Table 7) $[11,12,22,23]$.

\section{Clinical symptoms}

We also explored symptoms association with SARS-CoV-2 positivity (Table 8). Symptoms data was available from two sero-prevalence studies for both students and staff $[11,12]$. Study participants who had experienced major symptoms were more likely to test positive, compared to those who had had minor or no symptoms $(27.09 \%, 10.98 \%$, and $8.98 \%$, respectively, $P<0.001)$. Fever, cough, dyspnea, ageusia, anosmia, rhinitis, sore throat, headache, myalgia, asthenia, and diarrhoea were all associated with the detection of SARS-CoV-2 antibodies (Table 8). The most frequently reported symptoms were anosmia 84.27\% (95\% $\mathrm{CI}=76.64 \%-90.59 \%)$, ageusia $79.58 \%$ (95\% CI $=58.86 \%$ $94.50 \%)$, myalgia 30.61\% (95\% CI $=11.05 \%-54.74 \%)$, fever $29.88 \%$ (95\% CI $=8.32 \%-57.73 \%$ ), and diarrhoea $29.15 \%$ (95\% CI $=8.74 \%-55.32 \%)$.

Table 7. Gender differences in SARS-CoV-2 infection attack rate and positivity rate

\begin{tabular}{|c|c|c|c|c|c|c|c|c|c|c|c|c|}
\hline Study type & NuMBER OF STUDIES & N (POSIIIVE CASES) & N (MALE) & $\begin{array}{l}\text { N (POSIIIIVE } \\
\text { CASES) }\end{array}$ & $\mathbb{N}$ (FEMALE) & $\begin{array}{l}\text { OR (MALE } \\
\text { vs FEMALE) }\end{array}$ & $95 \%$ CI & $P_{\text {-value }}$ & $\begin{array}{c}\text { Cochrame } \\
\mathbf{Q}\end{array}$ & $I^{2}$ & TAU-Square & P-Egetr \\
\hline \multicolumn{13}{|c|}{ Cohort (IAR) } \\
\hline & 1 & 7 & 594 & 7 & 854 & 1.44 & $0.50-4.14$ & 0.49 & NA & NA & NA & NA \\
\hline & 4 & 268 & 2082 & 359 & 2475 & 0.90 & $0.72-1.13$ & 0.36 & 4.96 & 39.5 & 0.02 & 0.01 \\
\hline
\end{tabular}

$\mathrm{CI}$ - confidence interval, IAR - infection attack rate, OR - odds ratio, NA - not applicable

\section{Study quality}

We considered contact-tracing studies as potential controlled cohort studies with the contacts of the index case representing the exposed group and the non-contacts who were in the school environment representing the unexposed group (a proxy community control group). Studies performed well in terms of representativeness of the groups and comparability. All studies employed active symptom screening in the exposed group with four of five studies employing passive or no screening in the unexposed groups and no testing. This difference in screening and testing introduces a risk of measurement bias. In a single study of three schools in Singapore [19], both the exposed and unexposed groups underwent PCR testing regardless of symptoms. Follow-up rates were reported for the exposed groups with less than $80 \%$ follow-up for all studies introducing a high risk of attrition bias across studies (Table 9).

For cross-sectional studies, we noted that while the sample for the target school population was representative, four out of six studies experienced poor response rates, introducing selection bias. Studies performed variably across other domains (Table 10).

\section{DISCUSSION}

This systematic review summarizes the most recently available evidence to understand SARS-CoV-2 transmission in schools and includes an assessment of study quality to aid interpretation. The results from cohort and cross-sectional studies found that the overall IAR and SARS-CoV-2 positivity rate in school settings are low, and confirmed that students reported both lower IAR and SARS-CoV-2 positivity rate compared to school staff. However, the quality of studies limits our confidence in the observed results. 
Table 8. Clinical symptoms

Cross-setional studies $(\mathbb{N}=2)$

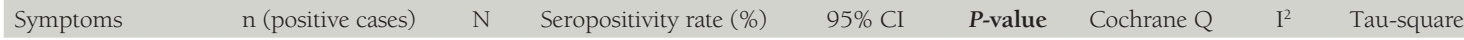
Symptom severity:

\begin{tabular}{|c|c|c|c|c|c|c|c|c|c|}
\hline None & & 61 & 811 & 8.98 & 2.38-19.09 & & 13.97 & 92.80 & 0.01 \\
\hline Minor & & 37 & 357 & 10.98 & $3.75-21.22$ & & 6.57 & 85.20 & 0.01 \\
\hline Major & & 212 & 833 & 27.09 & $10.23-48.36$ & $<0.001$ & 40.17 & 97.50 & 0.02 \\
\hline \multirow[t]{2}{*}{ Ageusia } & Yes & 93 & 118 & 79.58 & $58.86-94.50$ & $<0.001$ & 6.16 & 83.80 & 0.02 \\
\hline & No & 217 & 1883 & & & & & & \\
\hline \multirow[t]{2}{*}{ Anosmia } & Yes & 91 & 108 & 84.27 & $76.64-90.59$ & $<0.001$ & 0.03 & 0.00 & 0.00 \\
\hline & No & 219 & 1893 & & & & & & \\
\hline \multirow[t]{2}{*}{ Asthenia } & Yes & 135 & 513 & 27.79 & $13.02-45.55$ & $<0.001$ & 17.27 & 94.20 & 0.02 \\
\hline & No & 175 & 1488 & & & & & & \\
\hline \multirow[t]{2}{*}{ Cough } & Yes & 127 & 581 & 22.91 & $8.15-42.29$ & $<0.001$ & 25.24 & 96.00 & 0.02 \\
\hline & No & 183 & 1420 & & & & & & \\
\hline \multirow[t]{2}{*}{ Diarrhoea } & Yes & 65 & 238 & 29.15 & $8.74-55.32$ & $<0.001$ & 16.70 & 94.00 & 0.03 \\
\hline & No & 245 & 1763 & & & & & & \\
\hline \multirow[t]{2}{*}{ Dyspnoea } & Yes & 60 & 213 & 28.58 & $16.79-42.03$ & $<0.001$ & 4.29 & 76.70 & 0.01 \\
\hline & No & 250 & 1788 & & & & & & \\
\hline \multirow[t]{2}{*}{ Fever } & Yes & 127 & 461 & 29.88 & $8.32-57.73$ & $<0.001$ & 36.22 & 97.20 & 0.04 \\
\hline & No & 183 & 1540 & & & & & & \\
\hline \multirow[t]{2}{*}{ Headache } & Yes & 126 & 525 & 25.57 & 7.81-49.08 & $<0.001$ & 31.25 & 96.80 & 0.03 \\
\hline & No & 184 & 1476 & & & & & & \\
\hline \multirow[t]{2}{*}{ Myalgia } & Yes & 109 & 366 & 30.61 & $11.05-54.74$ & $<0.001$ & 22.59 & 95.60 & 0.03 \\
\hline & No & 201 & 1635 & & & & & & \\
\hline \multirow[t]{2}{*}{ Rhinitis } & Yes & 117 & 506 & 22.37 & $6.72-43.70$ & $<0.001$ & 27.56 & 96.40 & 0.03 \\
\hline & No & 193 & 1495 & & & & & & \\
\hline Sore & Yes & 86 & 439 & 20.44 & $7.60-37.41$ & 0.007 & 15.57 & 93.60 & 0.02 \\
\hline throat & No & 224 & 1562 & & & & & & \\
\hline
\end{tabular}

Table 9. Quality assessment using the Newcastle-Ottawa Scale for cohort studies

\begin{tabular}{|c|c|c|c|c|c|c|c|c|c|c|}
\hline \multirow[b]{2}{*}{ Study ID } & \multicolumn{4}{|c|}{ Selection Bias } & \multicolumn{2}{|c|}{ Comparabiuty } & \multicolumn{2}{|c|}{ Detection Bias } & \multicolumn{2}{|c|}{ Attrition Bias } \\
\hline & $\begin{array}{c}\text { Represen- } \\
\text { tativeness } \\
\text { of exposed } \\
\text { group }\end{array}$ & $\begin{array}{l}\text { Representa- } \\
\text { tiveness of } \\
\text { unexposed } \\
\text { group }\end{array}$ & $\begin{array}{l}\text { Ascertainment } \\
\text { of exposure }\end{array}$ & $\begin{array}{l}\text { Outcome } \\
\text { not present } \\
\text { at start of } \\
\text { study }\end{array}$ & $\begin{array}{l}\text { Matching for } \\
\text { school } \\
\text { mitigation } \\
\text { policies }\end{array}$ & $\begin{array}{l}\text { Matching } \\
\text { for age }\end{array}$ & $\begin{array}{c}\text { Assessment } \\
\text { of SARS- } \\
\text { CoV-2 }\end{array}$ & $\begin{array}{l}\text { Confirma- } \\
\text { tion of SARS- } \\
\text { CoV-2 }\end{array}$ & $\begin{array}{l}\text { Adequacy } \\
\text { of length of } \\
\text { follow-up }\end{array}$ & $\begin{array}{l}\text { Loss-to- } \\
\text { follow-up } \\
\text { rate }\end{array}$ \\
\hline Danis 2020 [17] & * & $*$ & $*$ & NR & $*$ & $*$ & NR & NR & * & NR \\
\hline Heavey 2020 [18] & $*$ & $*$ & NR & NR & $*$ & $*$ & NR & NR & * & NR \\
\hline Yung 2020 [19] & $*$ & $*$ & $*$ & NR & $*$ & $*$ & NR & $*$ & $*$ & NR \\
\hline NCIRS 2020 [20] & $*$ & $*$ & $*$ & NR & $*$ & $*$ & NR & NR & $*$ & NR \\
\hline Macartney 2020 [21] & $*$ & $*$ & $*$ & NR & $*$ & $*$ & NR & NR & $*$ & NR \\
\hline
\end{tabular}

* - denotes that the study met the criteria; NR - denotes either that the study did not meet criteria or that it was not reported

Table 10. Quality assessment using a modified Newcastle-Ottawa Scale for cross-sectional studies

\begin{tabular}{|c|c|c|c|c|c|c|c|c|c|c|c|}
\hline \multirow[b]{2}{*}{ Study ID } & \multicolumn{2}{|c|}{ SELECtion BaAs } & \multicolumn{3}{|c|}{ Performance bias } & \multicolumn{3}{|c|}{ Detection bias } & \multirow{2}{*}{$\begin{array}{l}\text { ATtRition } \\
\text { BIAS } \\
\text { Percent- } \\
\text { age in } \\
\text { final anal- } \\
\text { ysis }\end{array}$} & \multicolumn{2}{|c|}{ Comparabiuty } \\
\hline & $\begin{array}{l}\text { Represen- } \\
\text { tativeness } \\
\text { of sample }\end{array}$ & $\begin{array}{l}\text { Percent- } \\
\text { age partic- } \\
\text { ipation }\end{array}$ & $\begin{array}{l}\text { Ascertain- } \\
\text { ment of } \\
\text { COVID-19 }\end{array}$ & $\begin{array}{c}\text { Confir- } \\
\text { mation of } \\
\text { COVID-19 }\end{array}$ & $\begin{array}{c}\text { Blinding } \\
\text { of asses- } \\
\text { sors to } \\
\text { prior ex- } \\
\text { posure }\end{array}$ & $\begin{array}{c}\text { Ascertain- } \\
\text { ment of ex- } \\
\text { posure to } \\
\text { COVID-19 }\end{array}$ & $\begin{array}{l}\text { Confirma- } \\
\text { tion of ex- } \\
\text { posure to } \\
\text { COVID-19 }\end{array}$ & $\begin{array}{c}\text { Blinding of } \\
\text { assessors to } \\
\text { COVID-19 } \\
\text { status }\end{array}$ & & $\begin{array}{l}\text { Compa- } \\
\text { rable in } \\
\text { school }\end{array}$ & $\begin{array}{l}\text { Compara- } \\
\text { ble in age }\end{array}$ \\
\hline Torres 2020 [23] & * & * & NR & NR & NR & * & NR & NR & NR & * & * \\
\hline Armann 2020 [24] & * & NR & * & $*$ & * & * & NR & * & NR & * & * \\
\hline Desmet 2020 [25] & * & NR & * & NR & NR & NR & NR & NR & * & * & * \\
\hline Fontanet 2020, High [11] & $*$ & NR & $*$ & $*$ & $*$ & * & NR & * & * & NR & NR \\
\hline Fontanet 2020,Primary [12] & * & NR & * & NR & * & * & NR & * & * & NR & NR \\
\hline Stein-Zamir 2020 [22] & * & * & * & NR & NR & * & NR & NR & * & * & * \\
\hline
\end{tabular}

* - denotes that the study met the criteria; NR - denotes either that the study did not meet criteria or that it was not reported 
Cohort studies reported limited evidence of SARS-CoV-2 transmission in school settings. Compiling the data from five studies of school exposures early in pandemic before lockdown, we report an overall IAR of $0.08 \%$ (95\% CI =0.00\%-0.86\%). Clusters in educational facilities were identified in one of the five reporting countries, and those that occurred were limited in number and size [21]. NSW did not close schools during the beginning of COVID-19 pandemic. Transmission rates of student-to-student, student-to-staff, staff-to-student and staff-to-staff were $0.31 \%, 0.97 \%, 1.49 \%$ and $4.38 \%$ respectively. Students reported lower IAR than school staff. In addition, there is uncertainty about in which grade school children are more likely susceptible to and transmit SARS-CoV-2. IARs for ECDC ( $<6$ years old), primary school (612 years old), and secondary school (12-18 years old) were $2.25 \%, 0.92 \%, 0.00 \%$ respectively in NSW. The data are limited to reach a consensus. However, the clusters in NSW demonstrated that classroom crowding and other factors related to physical distancing may play a role in the spread of SARS-CoV-2 under the school environment. Many countries such as Denmark, Austria, Finland, Norway have implemented various prevention and control measures [33] and those countries have smaller classroom sizes compared to Australia [34]. The remaining four studies in France (Les Contamines-Montjoie), Ireland, Singapore, Australia (NSW) reported that transmission rate from student-to-student, student-to-staff, staffto-student and staff-to-staff was 0.00\% [17-20]. The limited evidence available to quantify the extent of SARS-CoV-2 transmission in school settings, reflects the fact that cluster outbreaks have been studied and reported relatively infrequently in schools to date. Effective implementation of NPIs such as physical distancing, small-size class, cancellation of mass gatherings, and hand hygiene is likely to further limit our ability to study school transmission [6].

Cross-sectional studies estimated the proportion of SARS-CoV-2 positive cases, to give an insight into how many people have been infected in schools. As described above, the positivity results in the general study population under school environment varied from 0.00 (lowest in eight daycare centers in Belgium) to 25.87\% (highest in one high school in France), which is likely to reflect the community positivity rate at the time the study was conducted [11,12,22-25]. The lower positivity rate in students suggested that students are less susceptible to infection and/or less frequently infected than adult school staff, which indicated that students are not at higher risk of causing super-spreading events in schools. Our finding is in line with many previous studies comparing sero-prevalence between children and adults [35-39]. However, the quality of the included studies is low and we should interpret the result with caution. Sero-prevalence results from Sweden in which schools remained open, demonstrated that 5-19 year-olds (6.0\%, 95\% CI 2.3\%-10.2\%) children had similar sero-prevalence to 20-49 year-olds (8.5\%, 95\% CI 4.99-11.7) adults [40]. We suggest more specialised and large-scale sero-surveillence studies need to be conducted to monitor SARS-CoV-2 infection during school opening. In addition, there is no consensus about in which grade school children have higher susceptibility to SARS-CoV-2 Infection. SARS-CoV-2 positive rates for pre-school ( $<6$ years old), primary school (6-12 years old), middle school and high school (12-18 years old) were $12.24 \%, 10.84 \%, 11.80 \%$ and $5.69 \%$ in Chile (Santiago). The peak rate was observed in preschool. By comparison, SARS-CoV-2 positive rates were $8.82 \%$ in primary schools (6-12 years old) in France (Crépy-en-Valois), and were $0.72 \%$ in middle schools (12-16 years old) in Germany (Saxony), and $38.33 \%$ in high schools (12-18 years old) in France, $13.18 \%$ in high schools (12-18 years old) in Israel.

A single study in Israel investigated whether school transmission increased relative to community transmission. Compared with the school-closure period, the total number of COVID-19 cases increased, and the proportion of infected children increased from $19.8 \%$ to $40.9 \%$ in the community. However, the role of school in the significant COVID-19 increase in the community was unclear because school re-opening coincided with the relaxation of other prevention and control measures [22].

We did not find any gender differences for secondary infection and SARS-CoV-2 positivity in schools. The lack of sex-disaggregated data for student and school staff specifically in the reviewed studies enhanced the difficulty to further explore potential explanations for the findings in gender.

The main clinical symptoms for COVID-19 patients were anosmia (84.3\%), ageusia (79.9\%), myalgia (30.6\%), fever (29.9\%), diarrhoea (29.2\%), dyspnea (28.6\%), and cough (22.9\%). We should interpret the result with caution because the symptom data only come from two sero-surveillance studies carried out in one high school $(n=661)$ and six primary schools $(n=1340)$ in France (Crépy-en-Valois). Studies from Italy [41-43], Germany [44], UK [45], Turkey [46] and Sweden [47] also reported similar clinical symptoms in children. In addition to common respiratory symptoms, gastrointestinal symptoms such as diarrhoea were present in around $25 \%$ of pediatric patients [48]. It is noted that the persistent shedding of SARS-CoV-2 in stools of infected children has been consistently reported, showing that SARS-CoV-2 may be present in the gastrointestinal tract for a longer duration than viral presence in the respiratory system, compared to adults [49-51]. 
The main strength of this study is that it provides a critical assessment of the published epidemiological evidence on SARS-CoV-2 transmission risk in the school environment. In addition, we estimated pooled IARs and SARS-CoV-2 positivity rates for students and school staff, and to our best knowledge, this is the first meta-analyses conducted, to investigate what is the rate of SARS-CoV-2 transmission in schools. However, the following potential limitations should be considered. First, further interpretation of agegroup differences in IARs and positivity rates could not be performed because 80.0\% (4/5) of included cohort studies and $50.0 \%$ (3/6) of included cross-sectional studies did not specify the ages of students and school staff. The remaining four included studies did not provide the raw data and we could not unify different age groups to run the meta-analysis. Second, cross-comparisons between IARs and positivity rates reported in different regions/countries is difficult because of differences in the sampling and testing methods used, timing of the studies in relation to the outbreak, response measures and underlying community transmission. Moreover, the differences may contribute to the heterogeneity observed in the meta-analyses results and raise methodological concerns around the validity of the meta-analysis. Due to the limited number of included studies, we could not conduct subgroup meta-analyses to further investigate the heterogeneity. As this is a living review, we anticipate that with the addition of more, well-conducted studies over time, heterogeneity may improve. Third, only two studies in the included 11 studies (18.2\%) reported prevention and control measures in place in schools such as class size, physical distancing, and staggered class start and end times, making it difficult to further investigate the effectiveness of NPIs under the school environment. Forth, only one study (9.1\%) compared school transmission rate with community transmission rate. Few studies have assessed the impact of school opening on transmission outside the school. Thus, we additionally searched study's background sero-prevalence or SARSCoV-2 case rate per 100000 population online, however, the data are limited. We suggest future studies could investigate this research question: does school increase or decrease transmission to the community. Fifth, although there is no evidence for publication bias, the number of included studies were less than ten. When there are fewer studies, the power of the tests is too low to distinguish chance from real asymmetry. Therefore, results should be interpreted with caution. Lastly, the majority of included studies are pre-print publications and have not been peer-reviewed. The quality of the included studies is low and we should interpret the results with caution.

\section{CONCLUSION}

In conclusion, although there is limited evidence available to quantify the extent of SARS-CoV-2 transmission in schools, the balance of evidence so far indicates that the overall IAR and SAR-CoV-2 positivity rate in the school environment are low. Specifically, lower IAR and positivity rates were reported in students compared to school staff, but poor study quality limits our overall confidence in these results. However, it is important to implement effective NPIs such as physical distancing, small-size class to prevent schools from becoming a setting for accelerating onward transmission during the re-opening of schools.

Acknowledgements: UNCOVER (Usher Network for COVID-19 Evidence Reviews) authors that contributed to this review are: Prof Harry Campbell, Dr Ruth McQuillan, Prof Harish Nair, Ms Emilie McSwiggan, Prof Gerry Fowkes. https://www.ed.ac.uk/usher/uncover.

Funding: ET is supported by a Cancer Research UK Career Development Fellowship (C31250/A22804). AK is supported by a Wellcome Trust Clinical PhD Programme Fellowship with grant reference: 203919/Z/16/Z. UNCOVER group is supported by Wellcome Trust's Institutional Strategic Support Fund (ISSF3) and by DDI.

Authorship contributions: The UNCOVER group conceived this study. XL, WX, MD, YH, ZL and AK conducted literature review. WX and XL performed meta-analyses. NS and CM developed the quality assessment tools and conducted quality assessment. WX and XL wrote the draft of the paper with input from all co-authors. ET, NS and $\mathrm{CM}$ provided methodological guidance on conducting the review. All authors have read and approved the final manuscript as submitted.
}

Competing interests: The authors completed the ICMJE Unified Competing Interest form (available upon request from the corresponding author), and declare no conflicts of interest.

Additional material

Online Supplementary Document 
1 WHO Coronavirus Disease (COVID-19) Dashboard. Available: https://covid19.who.int/. Accessed: 17 September 2020.

2 Viner RM, Russell SJ, Croker H, Packer J, Ward J, Stansfield C, et al. School closure and management practices during coronavirus outbreaks including COVID-19: a rapid systematic review. Lancet Child Adolesc Health. 2020;4:397-404. Medline:32272089 doi:10.1016/S2352-4642(20)30095-X

$3 \mathrm{Li}$ X, Xu W, Dozier M, He Y, Kirolos A, Theodoratou E. The role of children in transmission of SARS-CoV-2: A rapid review. J Glob Health. 2020;10:011101. Medline:32612817 doi:10.7189/jogh.10.011101

4 Ludvigsson JF. Systematic review of COVID-19 in children shows milder cases and a better prognosis than adults. Acta Paediatr. 2020;109:1088-95. Medline:32202343 doi:10.1111/apa.15270

5 Li X, Xu W, Dozier M, He Y, Kirolos A, Theodoratou E. The role of children in the transmission of SARS-CoV2: updated rapid review. J Glob Health. 2020;10:021101. doi:10.7189/jogh.10.021101

6 Royal Society DELVE Initiative. Balancing the Risks of Pupils Returning to Schools. Available: https://rs-delve.github.io/ reports/2020/07/24/balancing-the-risk-of-pupils-returning-to-schools.html\#fn:49. Accessed: 17 September 2020.

7 Moher D, Shamseer L, Clarke M, Ghersi D, Liberati A, Petticrew M, et al. Preferred reporting items for systematic review and meta-analysis protocols (PRISMA-P) 2015 statement. Syst Rev. 2015;4:1. Medline:25554246 doi:10.1186/20464053-4-1

8 Protocol: What is the evidence for transmission of COVID-19 by children in schools? A living systematic review. Available: https://www.crd.york.ac.uk/PROSPERO/display_record.php?RecordID=192839. Accessed: 11 September 2020.

9 DerSimonian R, Laird N. Meta-analysis in clinical trials. Control Clin Trials. 1986;7:177-88. Medline:3802833 doi:10.1016/0197-2456(86)90046-2

10 Freeman MF, Tukey JW. Transformations related to the angular and the square root. Ann Math Stat. 1950;21:607-11. doi:10.1214/aoms/1177729756

11 Fontanet A, Tondeur L, Madec Y, Grant R, Besombes C, Jolly N, et al. Cluster of COVID-19 in northern France: A retrospective closed cohort study. medRxiv. 2020. Available: https://www.medrxiv.org/content/10.1101/2020.04.18.2007 1134v1. Accessed: 17 September 2020.

12 Fontanet A, Grant R, Tondeur L, Madec Y, Grzelak L, Cailleau I, et al. SARS-CoV-2 infection in primary schools in northern France: A retrospective cohort study in an area of high transmission. medRxiv.2020. Available: https://www.medrxiv. org/content/10.1101/2020.06.25.20140178v2. Accessed: 17 September 2020.

13 Higgins JP, Thompson SG, Deeks JJ, Altman DG. Measuring inconsistency in meta-analyses. BMJ. 2003;327:557-60. Medline:12958120 doi:10.1136/bmj.327.7414.557

14 Egger M, Davey Smith G, Schneider M, Minder C. Bias in meta-analysis detected by a simple, graphical test. BMJ. 1997;315:629-34. Medline:9310563 doi:10.1136/bmj.315.7109.629

15 Wells GA, Shea B, O'Connell D, Peterson J, Welch V, Losos M, et al. The Newcastle-Ottawa Scale (NOS) for assessing the quality of nonrandomised studies in meta-analyses. Available: http://www.ohri.ca/programs/clinical_epidemiology/ oxford.asp. Accessed: 17 September 2020.

16 Siegfried N, Muller M, Deeks J, Volmink J, Egger M, Low N, et al. HIV and male circumcision-a systematic review with assessment of the quality of studies. Lancet Infect Dis. 2005;5:165-73. Medline:15766651 doi:10.1016/S14733099(05)70024-4

17 Danis K, Epaulard O, Bénet T, Gaymard A, Campoy S, Botelho-Nevers E, et al. Cluster of Coronavirus Disease 2019 (COVID-19) in the French Alps, February 2020. Clin Infect Dis. 2020;71:825-32. Medline:32277759 doi:10.1093/cid/ ciaa424

18 Heavey L, Casey G, Kelly C, Kelly D, McDarby G. No evidence of secondary transmission of COVID-19 from children attending school in Ireland, 2020. Euro Surveill. 2020;25:2000903. Medline:32489179 doi:10.2807/1560-7917. ES.2020.25.21.2000903

19 Yung CF, Kam KQ, Nadua KD, Chong CY, Tan NWH, Li J, et al. Novel coronavirus 2019 transmission risk in educational settings. Clin Infect Dis. 2020;ciaa794. Online ahead of print. Medline:32584975 doi:10.1093/cid/ciaa794

20 National Centre for Immunisation Research and Surveillance (NCIRS). COVID-19 in schools and early childhood education and care services - the Term 2 experience in NSW. Available: http://ncirs.org.au/sites/default/files/2020-08/ COVID-19\%20Transmission\%20in\%20educational\%20settings\%20in\%20NSW\%20Term\%202\%20report_0.pdf. Accessed: 11 September 2020.

21 Macartney K, Quinn HE, Pillsbury AJ, Koirala A, Deng L, Winkler N, et al. Transmission of SARS-CoV-2 in Australian educational settings: a prospective cohort study. Lancet Child Adolesc Health. 2020;4:807-16. Medline:32758454 doi:10.1016/S2352-4642(20)30251-0

22 Stein-Zamir C, Abramson N, Shoob H, Libal E, Bitan M, Cardash T, et al. A large COVID-19 outbreak in a high school 10 days after schools' reopening, Israel, May 2020. Euro Surveill. 2020;25:2001352. Medline:32720636 doi:10.2807/15607917.ES.2020.25.29.2001352

23 Torres JP, Piñera C, De La Maza V, Lagomarcino AJ, Simian D, Torres B, et al. SARS-CoV-2 antibody prevalence in blood in a large school community subject to a Covid-19 outbreak: a cross-sectional study. Clin Infect Dis. 2020;ciaa955. Online ahead of print. Medline:32649743

24 Armann JP, Unrath M, Kirsten C, Lueck C, Dalpke A, Berner R. Anti-SARS-CoV-2 IgG antibodies in adolescent students and their teachers in Saxony, Germany (SchoolCoviDD19): very low seropraevalence and transmission rates. medRxiv. 2020. Available: https://www.medrxiv.org/content/10.1101/2020.07.16.20155143v3. Accessed: 17 September 2020.

25 Desmet S, Ekinci E, Wouters I, Decru B, Beuselinck K, Malhotra-Kumar S, et al. No SARS-CoV-2 carriage observed in children attending daycare centers during the first weeks of the epidemic in Belgium. medRxiv. 2020. Available: https:// 
www.medrxiv.org/content/10.1101/2020.05.13.20095190v1. Accessed: 17 September 2020

26 WHO Coronavirus Disease (COVID-19) Dashboard: France. Available: https://covid19.who.int/region/euro/country/fr. Accessed: 17 September 2020

27 Ireland COVID-19 cases data. Available: https://www.gov.ie/en/publication/ce3fe8-previous-updates-on-covid-19-coronavirus/. Accessed: 17 September 2020

28 WHO Coronavirus Disease (COVID-19) Dashboard: Singapore. Available: https://covid19.who.int/region/wpro/country/sg. Accessed: 17 September 2020.

29 NSW COVID-19 cases data. Available: https://data.nsw.gov.au/nsw-covid-19-data/cases. Accessed: 17 September 2020.

30 WHO Coronavirus Disease (COVID-19) Dashboard: Chile. Available: https://covid19.who.int/region/amro/country/cl. Accessed: 17 September 2020.

31 WHO Coronavirus Disease (COVID-19) Dashboard: Germany. Available: https://covid19.who.int/region/euro/country/ de. Accessed: 17 September 2020.

32 WHO Coronavirus Disease (COVID-19) Dashboard: Belgium. Available: https://covid19.who.int/region/euro/country/ be. Accessed: 17 September 2020. 1.

33 Goldstein E, Lipsitch M, Cevik M. On the effect of age on the transmission of SARS-CoV-2 in households, schools and the community. medRxiv. 2020. Available: https://www.medrxiv.org/content/10.1101/2020.07.19.20157362v2. Accessed: 17 September 2020.

34 Organization for Economic Co-operation and Development. Average class size. Available: https://stats.oecd.org/Index. aspx?DataSetCode=EDU_CLASS. Accessed: 17 September 2020.

35 Pollán M, Pérez-Gómez B, Pastor-Barriuso R, Oteo J, Hernán MA, Pérez-Olmeda M, et al. Prevalence of SARS-CoV-2 in Spain (ENE-COVID): a nationwide, population-based seroepidemiological study. Lancet. 2020;396:535-44. Medline:32645347 doi:10.1016/S0140-6736(20)31483-5

36 Brotons C, Serrano J, Fernandez D, Garcia-Ramos C, Ichazo B, Lemaire J, et al. Seroprevalence against COVID-19 and follow-up of suspected cases in primary health care in Spain. medRxiv. 2020. Available: https://www.medrxiv.org/conte nt/10.1101/2020.06.13.20130575v1. Accessed: 17 September 2020.

37 Herzog S, De Bie J, Abrams S, Wouters I, Ekinci E, Patteet L, et al. Seroprevalence of IgG antibodies against SARS coronavirus 2 in Belgium: a prospective cross-sectional study of residual samples. medRxiv 2020. Available: https://www. medrxiv.org/content/10.1101/2020.06.08.20125179v3. Accessed: 17 September 2020.

38 Streeck H, Schulte B, Kuemmerer B, Richter E, Höller T, Fuhrmann C, et al. Infection fatality rate of SARS- CoV-2 infection in a German community with a super-spreading event. medRxiv 2020. Available: https://www.medrxiv.org/conten t/10.1101/2020.05.04.20090076v2. Accessed: 17 September 2020

39 Weis S, Scherag A, Baier M, Kiehntopf M, Kamradt T, Kolanos S, et al. Seroprevalence of SARS-CoV-2 antibodies in an entirely PCR-sampled and quarantined community after a COVID-19 outbreak-the CoNAN study. medRxiv 2020. Available: https://www.medrxiv.org/content/10.1101/2020.07.15.20154112v1. Accessed: 17 September 2020.

40 Stringhini S, Wisniak A, Piumatti G, Azman AS, Lauer SA, Baysson H, et al. Repeated seroprevalence of anti- SARSCoV-2 IgG antibodies in a population-based sample from Geneva, Switzerland. medRxiv 2020. Available: https://www. medrxiv.org/content/10.1101/2020.05.02.20088898v1. Accessed: 17 September 2020.

41 Parri N, Lenge M, Buonsenso D. Children with Covid-19 in Pediatric Emergency Departments in Italy. N Engl J Med. 2020;383:187-90. Medline:32356945 doi:10.1056/NEJMc2007617

42 Garazzino S, Montagnani C, Donà D, Meini A, Felici E, Vergine G, et al. Multicentre Italian study of SARS-CoV- 2 infection in children and adolescents, preliminary data as at 10 April 2020. Eurosurveillance. 2020;25. Medline:32400362 doi:10.2807/1560-7917.ES.2020.25.18.2000600

43 Romani L, Chiurchiù S, Santilli V, Bernardi S, Haywood Lombardi M, Scarselli A, et al. COVID-19 in Italian paediatric patients: The experience of a tertiary children's hospital. Acta Paediatr. 2020. Online ahead of print. Medline:32640088 doi:10.1111/apa.15465

44 Armann JP, Diffloth N, Simon A, Doenhardt M, Hufnagel M, Trotter A, et al. Hospital Admission in Children and Adolescents With COVID-19. Dtsch Arztebl Int. 2020;117:373-4. Medline:32519943

45 Kanthimathinathan HK, Dhesi A, Hartshorn S, Ali SH, Kirk J, Nagakumar P, et al. COVID-19: A UK Children's Hospital Experience. Hosp Pediatr. 2020;10:802-5. Medline:32518091 doi:10.1542/hpeds.2020-000208

46 Korkmaz MF, Türe E, Dorum BA, Kılıç ZB. The Epidemiological and Clinical Characteristics of 81 Children with COVID-19 in a Pandemic Hospital in Turkey: an Observational Cohort Study. J Korean Med Sci. 2020;35:e236. Medline:32597047 doi:10.3346/jkms.2020.35.e236

47 Hildenwall H, Luthander J, Rhedin S, Hertting O, Olsson-Åkefeldt S, Melén E, et al. Paediatric COVID-19 admissions in a region with open schools during the two first months of the pandemic. Acta Paediatr. 2020. Online ahead of print. Medline:32567145 doi:10.1111/apa.15432

48 ECDC. COVID-19 in children and the role of school settings in COVID-19 transmission. Available: https://www.ecdc. europa.eu/en/publications-data/children-and-school-settings-covid-19-transmission. Accessed: 17 September 2020.

$49 \mathrm{Xu} \mathrm{Y,} \mathrm{Li} \mathrm{X,} \mathrm{Zhu} \mathrm{B,} \mathrm{Liang} \mathrm{H,} \mathrm{Fang} \mathrm{C,} \mathrm{Gong} \mathrm{Y,} \mathrm{et} \mathrm{al.} \mathrm{Characteristics} \mathrm{of} \mathrm{pediatric} \mathrm{SARS-CoV-2} \mathrm{infection} \mathrm{and} \mathrm{potential} \mathrm{evi-}$ dence for persistent fecal viral shedding. Nat Med. 2020;26:502-5. Medline:32284613 doi:10.1038/s41591-020-0817-4

$50 \mathrm{Ma} \mathrm{X}$, Su L, Zhang Y, Zhang X, Gai Z, Zhang Z. Do children need a longer time to shed SARS-CoV-2 in stool than adults? J Microbiol Immunol Infect. 2020;53:373-6. Medline:32224116 doi:10.1016/j.jmii.2020.03.010

51 Xing YH, Ni W, Wu Q, Li WJ, Li GJ, Wang WD, et al. Prolonged viral shedding in feces of pediatric patients with coronavirus disease 2019. J Microbiol Immunol Infect. 2020;53:473-80. Medline:32276848 doi:10.1016/j.jmii.2020.03.021 